\title{
EVALUATION OF NEUROPROTECTIVE EFFECT OF AZILSARTAN AS MEMORY ENHANCER AGAINST SCOPOLAMINE AND SODIUM NITRITE-INDUCED AMNESIA IN SWISS ALBINO MALE RATS
}

\author{
CHANCHAL THAKUR*, VRISH DHWAJ ASHWLAYAN \\ Department of Pharmaceutical Technology, Meerut Institute of Engineering and Technology, Meerut, Uttar Pradesh, India. \\ Email: thakurchanchal63@gmail.com
}

Received: 06 August 2020, Revised and Accepted: 24 September 2020

\section{ABSTRACT}

Objective: The objective of the study was to assess the neuroprotective effect of azilsartan as a memory enhancer against scopolamine-induced amnesia in rats.

Methods: Albino Swiss male rats in equal numbers per group $(n=6)$ were taken. Scopolamine hydrobromide was administered to induce amnesia within the rats. Control group rats were administered normal, negative control groups were administered with scopolamine to induce amnesia and nitrite during trials, positive control group rats were administered piracetam+ scopolamine and piracetam nitrite during trials, and test control group rats were administered azilsartan +sodium nitrite and azilsartan nitrite. Exteroceptive behavioral models just like the elevated plus-maze model, Morris water maze model, acquisition trials, and retrieval trial were wont to evaluate the neuroprotective effect of azilsartan.

Results: The scopolamine and azilsartan have a significantly decreasing effect on time spent within the target quadrant (TSTQ) but piracetam has an increasing effect. The effect of azilsartan on transfer latency time (TLT) was observed against scopolamine-induced amnesia in rats using the elevated plus-maze test. Piracetam was found to decrease the TLT and restore memory function at a better dose. Within the case of scopolamine treated rats, a big increase in TLT was noted. Azilsartan treated group also increased TLT within the elevated plus maze. It is noted that the scopolamine features a significantly increasing effect on escape latency time (ELT). Piracetam features a decreasing effect on ELT. A rise in ELT was seen because of azilsartan.

Conclusion: This study suggested that the azilsartan features a significant decreasing effect on TSTQ, azilsartan treated group also increased TLT and ELT.

Keywords: Transfer latency time, Escape latency time, Time spent within the target quadrant, Piracetam, Scopolamine, Azilsartan.

(C) 2020 The Authors. Published by Innovare Academic Sciences Pvt Ltd. This is an open access article under the CC BY license (http://creativecommons. org/licenses/by/4. 0/) DOI: http://dx.doi.org/10.22159/ajpcr.2020.v13i11.39327

\section{INTRODUCTION}

Nootropics are drugs, supplements, and other substances which will improve cognitive function of the brain [1]. Nootropics also called smart drugs, memory enhancers, neuroenhancers, cognitive enhancers, and intelligence enhancers are drugs. Epidemiological studies of the Indian population reveal that dementia is essentially a hidden problem. Amnesia is often caused by a traumatic emotional event [2]. Today's memory impairment may be a major problem because of dementia in elder people [3]. There are two different nootropics: Synthetic, a lab-created compound like piracetam, and notable natural and herbal nootropics, like ginkgo bilobal and American ginseng. Natural nootropics are proven in boosting the brain function while at an equivalent time making the brain healthier. Nootropics act as a vasodilator against the tiny arteries and veins within the brain [4]. The introduction of natural nootropics within the system will increase the blood circulation to the brain and at an equivalent time provide the important nutrient and increase energy and oxygen flow to the brain [5]. A number of the natural nootropics act as a positive allosteric modulator for acetylcholine (Ach) or glutamate receptors [6]. Commercialized natural nootropics within the market are reacting at different mechanisms, thus affecting different parameters. Natural nootropics alter the concentration of existing neurotransmitters. Natural nootropics are disclosed to stimulate the discharge of dopamine, uptake of choline, cholinergic transmission, function of $\alpha$-amino3-hydroxy-5-methyl-4-isoxazole propionate receptor, turnover of phosphatidylinositol, and activity of phosphatase A2 [7]. Memory may be a process by which one encodes, stores, and retrieves information. Any disturbance within the process of acquisition/learning, retention, and recall, the three aspects end in the loss of cognitive ability with dementia in citizenry and amnesia in rodents, respectively [8]. Nitrite-induced severe vasodilatation and methemoglobinemia are responsible to supply cerebral hypoxia in experimental rodents. Scopolamine, the centrally acting anti-muscarinic drug with amnestic properties, has been used for many years in experimental animals to induce impairment in their performance of a spread of tasks requiring intact working and reference memory [9]. Scopolamine caused memory impairment, reduced cerebral blood flow, Ach level, elevated acetylcholinesterase activity, and malondialdehyde in rodents. Azilsartan may be a selective angiotensin II receptor antagonist utilized in the treatment of hypertension. The inhibition of the renin-angiotensin system (RAS) improves cognitive functions in hypertensive patients. RAS inhibition in hypertensive patients might be neuroprotective. Inhibition of the RAS could also be beneficial in attenuating cognitive deficits observed in aging, Alzheimer's disease, paralysis agitans, vascular cognitive impairment, and poststroke cognitive impairment [10]. Scopolamine, a centrally acting antimuscarinic drug, impairs learning and memory both in rat and citizenry. Loss of the Ach, a neurotransmitter within the brain of patients with Alzheimer's disease, appears to be a critical element to supply dementia. Ach was considered one among the neurochemical transmitters liable for memory retention. In humans, Ach, a key neurotransmitter for brain function, is synthesized locally within the cholinergic nerve endings [11].

\section{METHODS}

Drugs and chemicals

Piracetam ( $400 \mathrm{mg} / \mathrm{kg}$ ) and scopolamine $(0.400 \mathrm{mg} / \mathrm{kg}$ ) were purchased from Jain Diagnostic Pvt. Ltd., New Delhi. Normal saline $(10 \mathrm{mg} / \mathrm{kg})$, azilsartan $(10 \mathrm{mg} / \mathrm{kg})$, and nitrite $(75 \mathrm{mg} / \mathrm{kg})$ were purchased from 
Central Drug House (Pvt.) Laboratory (CDH), Daryaganj, New Delhi. All others unlabeled and reagents were analytical grade.

\section{Animal care and selection}

The normal weight of Swiss albino male rats was 150-200 g. The hotness of the experimental animal room was maintained to be $22^{\circ} \mathrm{C}$ $\left( \pm 3^{\circ} \mathrm{C}\right)$. Lighting was artificial, the sequence being $12 \mathrm{~h}^{\prime}$ light, $12 \mathrm{~h}$ ' dark. For feeding, conventional laboratory diets are used with water supplied. Healthy male rats are assigned to the control, standard, and action group. The protocol was accepted by the Institutional Animal Ethics panel (IAEC), approval no. MIET/IAEC/2019/JAN/16.

\section{Behavioral animal models}

Exteroceptive behavioral models

Morris water maze model: Morris water maze model is used to judge learning and memory. It consists of a circular cistern (diameter $150 \mathrm{~m}$ and height $45 \mathrm{~cm}$ ), stuffed with water maintained at $25^{\circ} \mathrm{C}$. The water is formed opaque with a white-colored dye. The tank is split into four equal quadrants with the assistance of two threads, fixed at the proper angle to every other on the rim of the pool. A platform $(10 \mathrm{~cm})$ of $29 \mathrm{~cm}$ height is found within the center of one of those four quadrants. The position of the platform and clues is kept consistent throughout the training session [12]

Acquisition trials: Within the acquisition trial after $1 \mathrm{~h}$ from drug administration, each rat was allowed in water for $120 \mathrm{~s}$ to search out the hidden platform from each quadrant and escape latency time (ELT), the time taken by rats to search out the hidden platform was noted. When a rat was unable to search out a hidden platform within $120 \mathrm{~s}$, then the ELT was noted to be $120 \mathrm{~s}$. After each trial, rats were stayed at the hidden platform for approx. $30 \mathrm{~s}$ to memorize the situation (Table 1 and Fig. 1) [9].

\section{Retrieval trial}

On the day of the retrieval trial, the hidden platform was removed and after $1 \mathrm{~h}$ of dosing each rat was allowed into the pool for $120 \mathrm{~s}$ from each quadrant and therefore the time spent within the Q4 target quadrant (time spent in target quadrant [TSTQ]) within $120 \mathrm{~s}$ was noted (Fig. 2).

\section{Elevated plus-maze model}

The elevated plus maze served because the exteroceptive (where stimulus existed outside the body) behavioral model to judge knowledge and memory in rats 13 . The apparatus consists of two open weapons $(15 \mathrm{~cm} \times 10 \mathrm{~cm})$ and two enclosed arms $(15 \mathrm{~cm} \times 10$ $\mathrm{cm} \times 14 \mathrm{~cm})$. The arms extended from a middle platform $(10 \mathrm{~cm} \times 10$ $\mathrm{cm}$ ), and therefore, the maze is elevated to a height of $50 \mathrm{~cm}$ from the ground. On the primary day, each rat is going to be placed at the top of an open arm, facing far from the central platform. Transfer latency time (TLT) is going to be the time taken by the rat to maneuver into anybody of the covered arms with all its four legs. TLT is recorded on the primary day. If the rats do not enter into one among the covered arms within $90 \mathrm{~s}$, they are going to be gently pushed into one among the two covered arms, and therefore, the TLT are going to be assigned as $90 \mathrm{~s}$. The rats are going to be allowed to explore the maze for $10 \mathrm{~s}$ then return to its home cage. Memory retention is going to be calculated $24 \mathrm{~h}$ of acquisition trial on the $2^{\text {nd }}$ day as inflation ratio using the subsequent formula described by inflation ratio = L1- L0/ L0 where L0 is TLT after $24 \mathrm{~h}$ and L1 is that the initial TLT in second (Fig. 3) [13].

\section{Table 1: Experimental groups for escape latency time}

\begin{tabular}{lll}
\hline Groups $(\mathbf{n = 6 )}$ & Treatments & Dose \\
\hline Control & Normal saline & $10 \mathrm{ml} / \mathrm{kg}^{2}$ \\
Negative control & Scopolamine & $0.4 \mathrm{mg} / \mathrm{kg}^{3}$ \\
Standard per se & Piracetam+Scopolamine & $400 \mathrm{mg} / \mathrm{kg}+0.4 \mathrm{mg} / \mathrm{kg}$ \\
Test drug & Azilsartan+Scopolamine & Low dose $10 \mathrm{mg}$ \\
Test drug & Azilsartan+Scopolamine & High dose $20 \mathrm{mg}$ \\
\hline
\end{tabular}

Introspective behavioral models

Induction of scopolamine-induced amnesia within the rat: Scopolamine hydrobromide $(0.3 \mathrm{mg} / \mathrm{kg}$, i.p.) was administered to induce amnesia. Scopolamine may be a muscarinic receptor antagonist with amnestic properties that are used for many years in experimental rats to induce impairment in their performance of a spread of tasks requiring intact working and reference memory. Scopolamine has also been second hand clinically as an adjunct to the surgical or obstetric procedure to induce sedation and post-procedural amnesia [14]. This reversible amnestic effect was induced by centrally acting muscarinic cholinergic antagonists. Indeed, blockade of central muscarinic receptors could induce a pattern of cognitive impairment. Scopolamine actions are limited to the blockade of brain function mediated through cholinergic (muscarinic) receptors. Scopolamine, however, is comparatively non-selective pharmacologically concerning receptor subtypes, and therefore, the drug does not discriminate considerably concerning receptor subtypes, and therefore, the drug does not discriminate considerably concerning brain region although the scopolamine reversal model is in wide use in preclinical stages of drug development, in clinical trials [15].

\section{Experimental protocol}

Rats used for time spent within the target quadrant (TSTQ) and TLT were allocated into nine experimental groups and every group contained six rats.

- Group 1: Control group: Rats were administered normal saline $(0.9 \%$ common salt solution; $10 \mathrm{ml} / \mathrm{kg}$, i.p.) hour before the acquisition trial for 4 consecutive days and hour before the retrieval trial on day 5

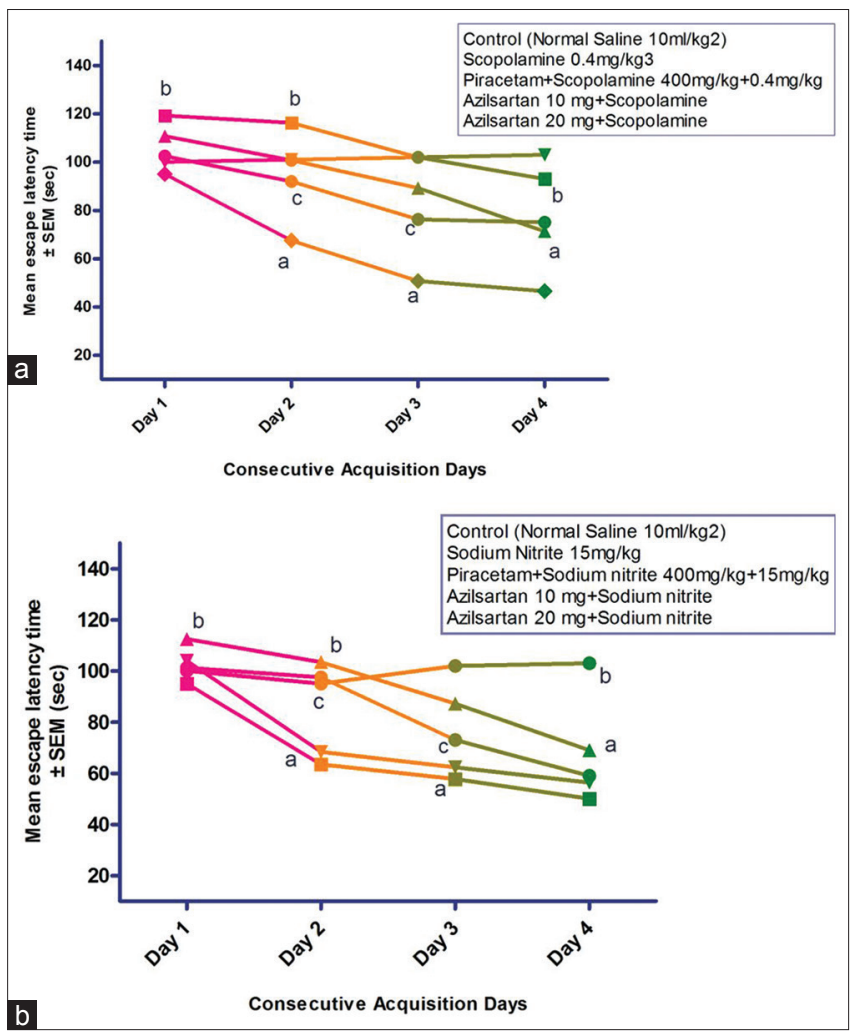

Fig 1: (a and b) Effect of azilsartan on ELT during acquisition trials trial. Group I - Control (normal saline), Group II - negative control (sodium nitrite), Group III - standard per se (piracetam+sodium nitrite), Group IV - test drug (test drug+sodium nitrite), Group

$\mathrm{V}$ - test drug (test drug+sodium nitrite) (significant increase $\left[{ }^{*} \mathbf{p}<0.0001\right]$ vs. control and significant decrease $\left[{ }^{\circledR} \mathbf{p}<0.0001\right]$ vs. treated group) 


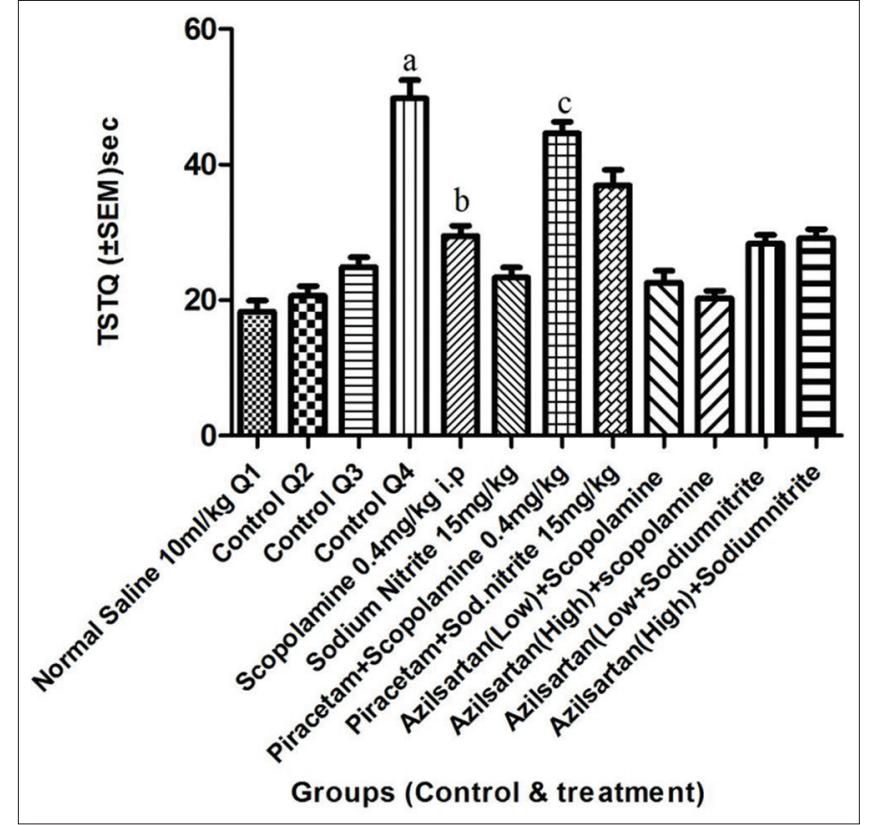

Fig. 2: Effect of azilsartan on time spent within the target quadrant during retrieval trial. Group I-IV - Control (normal saline), Group V - negative control (scopolamine), Group VI - negative control (sodium nitrite), Group VII - standard per se (piracetam+scopolamine), Group VIII standard per se (piracetam+sodium nitrite), Group IX - test drug (test drug+scopolamine), Group $\mathrm{X}$ - test drug (test drug+scopolamine), Group XI - test drug (test drug+sodium nitrite), Group XII - test drug (test drug+sodium nitrite) (significant increase $\left[{ }^{*} p<0.0001\right]$ vs. control and significant decrease $\left[{ }^{@} \mathbf{p}<0.0001\right]$ vs. treated group]

- Group 2: Negative control group: Rats were administered scopolamine $(0.4 \mathrm{mg} / \mathrm{kg}$; i.p.) during acquisition trials conducted from day 1 to day 4 then subjected to the Morris water maze test. On day 5 , rats were administered normal saline $(0.9 \%$ common salt solution; $10 \mathrm{ml} / \mathrm{kg}$, i.p.), then subjected to a retrieval trial after hour

- Group 3: Negative control group: Rats were administered nitrite (75 mg/kg i.p.) during acquisition trials conducted from day 1 to day 4 then subjected to the Morris water maze test

- Group 4: Positive control group (piracetam-treated group): Rats were administered piracetam (200 mg/kg, i.p.) + scopolamine $(0.4 \mathrm{mg} / \mathrm{kg}$ i.p.) during acquisition trials conducted from day 1 to day 4 so subjected to the Morris water maze test

- Group 5: Positive control group (piracetam-treated group): Rats were administered piracetam ( $400 \mathrm{mg} / \mathrm{kg}$ ) +sodium nitrite ( $75 \mathrm{mg} / \mathrm{kg}$ i.p.) during acquisition trials conducted from day 1 to day 4 then subjected to the Morris water maze test

- Group 6: Test control group: Rats were administered azilsartan $(10 \mathrm{mg} / \mathrm{kg}$; p.o) hour before and scopolamine $(0.4 \mathrm{mg} / \mathrm{kg}$, i.p.) halfhour before during acquisition trials conducted from day 1 to day 4 then subjected to Morris water maze test

- Group 7: Test control group: Rats were administered azilsartan $(20 \mathrm{mg} / \mathrm{kg}$; p.o) hour before and scopolamine $(0.4 \mathrm{mg} / \mathrm{kg}$, i.p.) halfhour before during acquisition trials conducted from day 1 to day 4 then subjected to Morris water maze test

- Group 8: Test control group: Azilsartan (10 mg/kg; i.p.) hour before and nitrite $(75 \mathrm{mg} / \mathrm{kg}$, p.o) half-hour before during acquisition trials conducted from day 1 to day 4 then subjected to Morris water maze test

- Group 9: Positive control group: Azilsartan $(20 \mathrm{mg} / \mathrm{kg}$; i.p.) hour before and nitrite ( $75 \mathrm{mg} / \mathrm{kg}$, p.o) half-hour before during acquisition trials conducted from day 1 to day 4 then subjected to Morris water maze test. Rats used for ELT were allocated into five experimental groups and every group contained six rats [16].

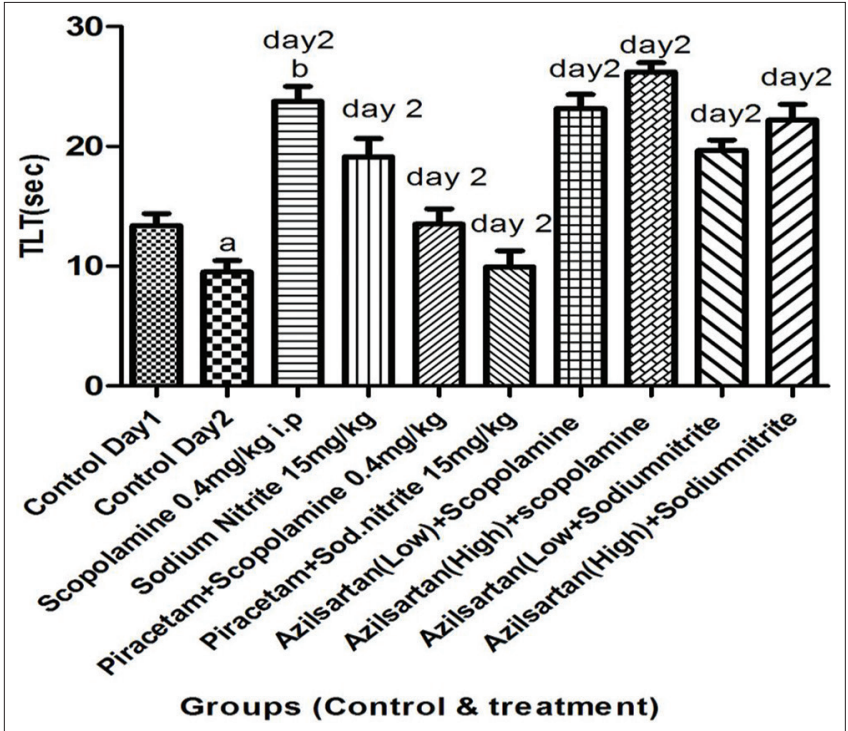

Fig. 3: Effect of azilsartan on transfer latency time by elevated plus maze method. Group I and II - control (normal saline), Group III - negative control (scopolamine), Group IV - negative control (sodium nitrite), Group V - standard per se (piracetam+scopolamine), Group VI - standard per se (piracetam+sodium nitrite), Group VII - test drug (test drug+scopolamine), Group VIII - test drug (test drug+scopolamine), Group IX - test drug (test drug+sodium nitrite), Group $X$ - test drug (test drug+sodium nitrite) (significant increase $[* p<0.0001]$ vs. control and significant decrease $\left[{ }^{\circledR} \mathbf{p}<0.0001\right]$ vs. treated group)

Statistical analysis

Statistical analysis was carried out using GraphPad Prism 5.0 (version 5.03). All the experimental data were expressed as mean \pm SEM. Result comparisons were carried out using a one-way analysis of variance followed by Tukey's multiple comparison test to compare means among the groups. For the statistical tests, $\mathrm{p}<0.05$ was considered to be statistically significant.

\section{RESULTS}

\section{Pharmacological screening using Morris water maze model}

Effect of Azilsartan on scopolamine and sodium nitrite-induced changes in ELT during acquisition trials

Azilsartan was investigated for its effect on scopolamine-induced amnesia and nitrite using the Morris water maze test. Azilsartan was administered at $10 \mathrm{mg} / \mathrm{kg}$, p. o. and $20 \mathrm{mg} / \mathrm{kg}$, p. o. doses in rats. The ELT of azilsartan conducted on 4 consecutive days is shown. It is noted that the scopolamine features a significantly increasing effect on ELT. Piracetam features a decreasing effect on ELT. Increase in ELT was seen because of azilsartan.

Effect of azilsartan on scopolamine and sodium nitrite-induced changes in TSTQ during retrieval trial by Morris water maze method

Azilsartan was investigated for its effect on scopolamine-induced amnesia using the Morris water maze test. Azilsartan was administered at $10 \mathrm{mg} / \mathrm{kg}$, p. o. and $20 \mathrm{mg} / \mathrm{kg}$, p. o. doses in rats. The TSTQ of azilsartan is shown. Note that while the scopolamine and azilsartan features a significant decreasing effect on TSTQ but piracetam has an increasing effect. Scopolamine treated rat's decreased TSTQ as compared to the target quadrant (Q4) of the control group. However, piracetam increased TSTQ and showed protection against scopolamineinduced amnesia. Results were expressed as mean \pm S.E.M. with $\mathrm{n}=6$ in each group. $a=p \leq 0.05$ versus TSTQ within the control group; $b=p \leq 0.05$ versus TSTQ in scopolamine-treated group. 
Effect of Azilsartan on scopolamine and sodium nitrite-induced changes in TLT of rats by Elevated plus-maze method

The effect of azilsartan on TLT at doses of $10 \mathrm{mg} / \mathrm{kg}$, p.o. and $20 \mathrm{mg} / \mathrm{kg}$, p.o. was observed against scopolamine-induced amnesia in rats using the elevated plus-maze test. Piracetam was found to decrease the TLT and restore memory function at a better dose. In the case of scopolaminetreated rats, a major increase in TLT was noted. Azilsartan-treated group also increased TLT in elevated plus maze. Results were expressed as mean \pm S.E.M. with $n=6$ in each group. $a=p \leq 0.05$ versus TLT up to the mark group; $b=p \leq 0.05$ versus TLT in scopolamine-treated group.

\section{DISCUSSION}

Most of the smart drugs are related to psychotic drugs with the specific site of action on the receptor of brain and memory. Piracetam was used as standard medicine to reverse the memory deficit by scopolamine. Piracetam is a drug commonly used to treat amnesia and is also used for the treatment of Alzheimer disease [7]. Scopolamine-induced amnesia test was used as an interoceptive model to induce amnesia in rats and the Morris water maze test and elevated plus maze test were used as an exteroceptive model. In Morris water maze test, acquisition trials animals learned to find a hidden platform to escape from water ELT and in the retrieval trial on the $5^{\text {th }}$ day the highest TSTQ (Q4) shows the retrieval of memory [11]. Scopolamine produced impairments of memory in both acquisition trials and retrieval trials by increasing the ELT and decreasing the TSTQ. The azilsartan was investigated for its effect on scopolamineinduced amnesia using the Morris water maze test. After the injection of scopolamine $(0.4 \mathrm{mg} / \mathrm{kg}$, i.p.), rats showed impairment of memory compared to that of the control group in which the little change in ELT was noted to find the hidden platform [17]. Azilsartan was administered at different doses $(10 \mathrm{mg} / \mathrm{kg}$, p.o. and $20 \mathrm{mg} / \mathrm{kg}$, p.o $)$, decrease in ELT to find the hidden platform, and the time spent by the rats in the target quadrant was taken as the index of retrieval. Further estimation of TLT was done with the help of elevated plus maze [18]. TLT was measured on 4 and 5 days of study. Azilsartan-treated group also increased TLT in elevated plus maze. Note that while the scopolamine and azilsartan have a significant decreasing effect on TSTQ but piracetam has an increasing effect. Azilsartan was found to increase the TLT [19].

\section{CONCLUSION}

Memory enhancing effect of azilsartan was investigated against scopolamine-induced amnesia in rats applying MWM test and EPM tests. Azilsartan was given at the dose of $10 \mathrm{mg} / \mathrm{kg}$, p.o. and $20 \mathrm{mg} / \mathrm{kg}$, p.o. Scopolamine was given at the dose of $0.4 \mathrm{mg} / \mathrm{kg}$, i.p. before the test, drug to induce amnesia. An increase in ELT during acquisition trials and a decrease in TSTQ in retrieval trial show that azilsartan does not have memory enhancing property. Hence, both the screening models clarified that it does not have any kind of nootropic effect.

\section{ACKNOWLEDGMENT}

The first author Chanchal is thankful to Dr. Vrish Dhwaj Ashwlayan (Associate Professor) at the Department of Pharmaceutical Technology, MIET, Meerut, India, for providing general support and encouraging my work.

\section{AUTHORS' CONTRIBUTIONS}

Chanchal - Protocol preparation, data collection, correspondence, editing, and review. Dr. Vrish Dhwaj Ashwlayan - Protocol preparation, data collection, data analysis, statistical analysis, manuscript preparation, editing, and review.

\section{CONFLICTS OF INTEREST}

There are no conflicts of interest.

\section{AUTHORS' FUNDING}

No special grant has been obtained from any state, private, or supporting organization for this study.

\section{REFERENCES}

1. Frati P, Kyriakou C, Del Rio A, Marinelli E, Vergallo GM, Zaami S, et al. Smart drugs and synthetic androgens for cognitive and physical enhancement: Revolving doors of cosmetic neurology. Curr Neuropharmacol 2015; 13:5-11

2. Dartigues JF, Carcaillon L, Helmer C, Lechevallier N, Lafuma A, Khoshnood B. Vasodilators and nootropics as predictors of dementia and mortality in the Paquid cohort. J Am Geriatr Soc 2007:55:395-9.

3. Kessler J, Thiel A, Karbe H, Heiss WD. Piracetam improves activated blood flow and facilitates rehabilitation of poststroke aphasic patients. Stroke 2000;31:2112-6.

4. Oyaizu M, Narahashi T. Modulation of the neuronal nicotinic acetylcholine receptor-channel by the nootropic drug nefiracetam. Brain Res 1999;822:72-9.

5. Garvey DS, Wasicak JT, Decker MW. Novel isoxazoles which interact with brain cholinergic channel receptors have intrinsic cognitive enhancing and anxiolytic activities. J Med Chem 1994;37:1055-9.

6. Tota S. Role of central angiotensin receptors in scopolamine-induced impairment in memory, cerebral blood flow, and cholinergic function. Psychopharmacology (Berl) 2012;222:185-202.

7. Hampson RE, Rogers G, Lynch G, Deadwyler SA. Facilitative effects of the ampakine CX516 on short-term memory in rats: Correlations with hippocampal neuronal activity. J Neurosci 1998;18:2748-63.

8. Morris RG. Developments of a water-maze procedure for studying spatial learning in the rat. J Neurosci Methods 1984;11:47-60.

9. Sharma AC, Kulkarni SK. Reversal of scopolamineand dizocilpineinduced memory dysfunction by angiotensin converting enzyme inhibitors in rats and mice. Indian J Pharmacol 1992;24:147-53.

10. Okawa H, Ohishi N, Yagi K. Assay for lipid peroxides in animal tissues by thiobarbituric acid reaction. Anal Biochem 1979;95:351-8.

11. Nickerson M. Drugs. In: Goodman LS, Gilman A. The Pharmacological Basis of Therapeutics. New York: Macmillan Company; 2013. p. 727-43

12. Safer DJ, Allen RP. The central effects of scopolamine in man. Biol Psychiatry 1971;3:347-55

13. D'Hooge R, De Deyn PP. Applications of the Morris water maze in the study of learning and memory. Brain Res Rev 2001;36:60-90.

14. Itoh J, Nabeshima $T$, Kameyama T. Utility of an elevated plus maze for the evaluation of memory in mice: Effects of nootropics, scopolamine and electroconvulsive shock. Psychopharmacology (Berl) 1984;101:27-33

15. Jo YS, Park EH, Kim IH, Park SK, Kim H, Kim HT, et al. The medial prefrontal cortex is involved in spatial memory retrieval under partialcue conditions. J Neurosci 2007;27:13567-78.

16. Lee AC, Robbins TW, Pickard JD, Owen AM. Asymmetric frontal activation during episodic memory: The effects of stimulus type on encoding and retrieval. Neuropsychologia 2000;38:677-92.

17. Parle M, Singh N. Animal models for testing memory. Asia Pac J Pharmacol 2014;16:101-20.

18. Bhardwaj A, Kumar R, Dabas V, Alam N. Evaluation of anti-ulcer activity of Citrullus lanatus seed extract in Wistar albino rats. Int $\mathrm{J}$ Pharm Pharm Sci 2012;4:135-9.

19. Bhardwaj A, Kumar R, Dabas V, Alam N. Assessment and enhancing adherence to treatment regimen in tuberculosis out patients. Int J Pharm Pharm Sci 2012:4:517-22. 